\section{Ophthalmoplegia, amblyopia, and diffuse encephalomyelitis associated with pelvic abscess}

Duke-Elder ${ }^{1}$ included focal sepsis as a cause of optic neuritis, though he thought the association was uncommon. We describe here a patient who presented with optic neuritis with no apparent cause but whose neuro-ophthalmological symptoms disappeared after removal of a pelvic abscess.

\section{Case report}

An 18-year-old girl was admitted with a two-week history of headaches, backache, neck stiffness, and hyperacusis. One week before admission she developed intermittent diplopia, failing vision, and ataxia. Her last period had occurred three and a half months earlier. There was no history of drug abuse.

On examination she was feverish, drowsy, slow, and inconsistent in her replies. She had mild neck stiffness and a positive Kernig's sign. There were no marks of injection, bruises, abrasions, rash, or lymphadenopathy. There was a retrouterine mass, the size of a four-month pregnancy, which was fixed, non-tender, and firm.

Neurologically the eyes were immobile on all forms of testing, and the pupils were slightly divergent, irregular, and dilated and did not react to light. She could just detect hand movements but suffered no localised field loss. Examination of the fundi showed bilateral, sharply defined, whitish exudates over the disc and distension of surrounding vessels. There were no haemorrhages and the peripheral vessels were normal. Apart from mild deafness the remaining cranial nerves were normal but her arms were ataxic and she could not stand. All tendon jerks were reduced and the plantar responses were flexor.

Investigations showed a leucocytosis of $23 \times 10^{9} / 1$ with $89 \%$ polymorph and an erythrocyte sedimentation rate of $76 \mathrm{~mm}$ in first hour. Abdominal radiographs showed no pelvic calcification and pregnancy tests gave negative results. Chest and skull radiographs, right carotid angiogram, bilatera cavernous venograms, and EMI scan were all normal. Initial lumbar cerebrospinal fluid (CSF) examination showed normal pressure, cells, and biochemical values. An electroencephalogram showed widespread disorganisation with no specific features.

After treatment with ampicillin and ACTH the fever settled but her leve of consciousness and peripheral signs fluctuated. The fundal appearances changed, becoming pinker and more oedematous with venous congestion resembling plerocephalic oedema. Repeat lumbar puncture after three days confirmed that the CSF pressure had risen to $300 \mathrm{~mm} \mathrm{H}_{2} \mathrm{O}$ but otherwise it remained normal. Treatment with metronidazole was started and her level of consciousness and peripheral neurological signs improved. When metronidazole was stopped after a further 10 days she deteriorated with a swinging temperature. At laparotomy a right sterile pyosalpinx was removed together with the left ovary and fallopian tube, which were affected by several smal abscesses. Her mental state and eye movements recovered. The papilloedema resolved and visual acuity returned to normal.

Three months later she complained of gradual loss of sight: visual acuity was $6 / 36$ on the right and $6 / 12$ on the left. The optic discs were pale and the physiological cup obliterated. Perimetry showed concentric contraction in both eyes but no scotoma. Pupillary reflexes were present and eye movements were full, and there were no other neurological signs.

\section{Discussion}

This patient initially presented with optic neuritis and a normal CSF pressure, though the subsequent rise in CSF pressure contributed to later swelling of the optic disc. Screening tests for toxic substances, viruses, and specific diseases known to be associated with optic neuritis were negative, and the CSF findings together with the intermittent but symmetrical signs of central nervous system disease made embolic abscess or basal meningitis unlikely. Though our theory remains unproved, we suspect that the pelvic abscess may have caused the optic neuritis. The improvement after metronidazole, the deterioration when the drug was stopped, and the subsequent improvement when the abscess was drained support this suggestion.

Though Duke-Elder ${ }^{1}$ considered that focal sepsis was only rarely associated with optic neuritis, other workers have found the two conditions associated in as many as $44 \%$ of cases. ${ }^{2}$ The presence of a pelvic abscess in this patient provides some further evidence of an occasional association between focal sepsis and widespread neuroophthalmological disorder.

We thank Professor $\mathbf{R}$ Hoffenberg for his help with the clinical management and this report.

1 Duke-Elder, S, System of Ophthalmology, Vol XII, Neuro-ophthalmology, p 69. London, Kimpton, 1972.

2 Wilmer, W H, Archives of Ophthalmology, 1930, 4, 817.

(Accepted 2 Fanuary 1979)

Midland Centre for Neurosurgery and Neurology, Smethwick

Warley, West Midlands B67 7]X

BERNARD WILLIAMS, CHM, FRCS, consultant neurosurgeon

Norfolk and Norwich Hospital, Norwich, Norfolk NR1 3SR

T N GHOSH, DO, FRCS, senior registrar in ophthalmology

Department of Medicine, Queen Elizabeth Hospital, Edgbaston, Birmingham B15 2TH

R A STOCKLEY, MD, MRCP, lecturer in medicine

\section{Absence of toxicity in cimetidine overdosage}

Cimetidine is a histamine $\mathrm{H}_{\mathbf{2}}$-receptor antagonist that is widely used in the treatment of peptic ulceration. We report four cases of selfpoisoning with this drug.

\section{Case reports}

(1) A 26-year-old man with a duodenal ulcer was admitted $2 \frac{1}{2}$ hours after allegedly taking 80 cimetidine tablets $(16 \mathrm{~g}), 30 \mathrm{mg}$ nitrazepam, and 10 tablets of aluminium hydroxide. He was slightly drowsy and complained of a dry mouth, which was confirmed on examination. No other abnormality was found. Some tablet material was recovered by gastric lavage. He developed slight epigastric discomfort which was relieved by milk, but otherwise he remained well and the dryness of his mouth disappeared within 18 hours The electrocardiogram and plasma urea, creatinine, electrolytes, and glucose concentrations, and the liver function test results were normal 20 hours after the overdose. The plasma cimetidine concentration, measured by a highpressure liquid chromatography method based on that of Randolph et al, ${ }^{1}$ was $57 \mathrm{mg} / \mathrm{l}(226 \mu \mathrm{mol} / \mathrm{l})$ at $3.2 \mathrm{~h}, 40 \mathrm{mg} / \mathrm{l}(159 \mu \mathrm{mol} / \mathrm{l})$ at $4.5 \mathrm{~h}$, and $3 \mathrm{mg} / \mathrm{l}$ $(12 \mu \mathrm{mol} / \mathrm{l})$ at $23.3 \mathrm{~h}$ after the overdose.

(2) A 42-year-old man claimed to have taken 98 cimetidine tablets with a lot of Guinness two hours before admission. His only complaint was of a dry mouth. His tongue looked dry and he smelled of alcohol, but examination was otherwise normal. The electrocardiogram on admission was normal. Vomiting was induced by ipecacuanha with return of tablet fragments. $\mathrm{He}$ remained well and was discharged after 12 hours. The plasma cimetidine concentration was $36 \mathrm{mg} / \mathrm{l}(143 \mu \mathrm{mol} / \mathrm{l})$ at $2 \mathrm{~h}$ and $2.3 \mathrm{mg} / \mathrm{l}(9 \mu \mathrm{mol} / \mathrm{l})$ at $11.5 \mathrm{~h}$ after the overdose.

(3) A 26-year-old man was admitted $1 \frac{1}{2}$ hours after taking 26 cimetidine tablets $(5.2 \mathrm{~g})$. He was observed for 10 hours but developed no abnormal symptoms or signs. Two hours after the overdose the plasma cimetidine concentration was $37 \mathrm{mg} / \mathrm{l}(147 \mu \mathrm{mol} / \mathrm{l})$

(4) Ten hours before admission a 37-year-old man allegedly took 30 cimetidine tablets $(6 \mathrm{~g})$ and two pints of beer. He developed no symptoms or signs of toxicity. The plasma cimetidine concentration was $4.5 \mathrm{mg} / \mathrm{l}$ (18 $\mu \mathrm{mol} / \mathrm{l})$ at $10 \mathrm{~h}$ and $2.9 \mathrm{mg} / \mathrm{l}(11 \mu \mathrm{mol} / \mathrm{l})$ at $12 \mathrm{~h}$.

\section{Comment}

A single 200-mg dose of cimetidine by mouth gives a peak plasma concentration of about $1 \mathrm{mg} / 1(4.0 \mu \mathrm{mol} / \mathrm{l})$ at one hour. ${ }^{1}$ Our patients had much higher concentrations without ill effect except for dryness of the mouth in two patients and drowsiness in one patient who had also taken nitrazepam. Gill2 described the case of a man who took about 15 cimetidine tablets four times a day for five days without untoward 
effect. Curtes and Develay ${ }^{3}$ reported on a patient who claimed to have taken $\mathbf{5 0}$ cimetidine tablets with several phenobarbitone and Peritrate tablets but who developed no symptoms or signs of toxicity. In neither case, however, was the plasma cimetidine concentration measured to confirm what had been taken.

During treatment with cimetidine bradycardia may occur occasionally, possibly due to blockade of $\mathrm{H}_{2}$-receptors in the heart. ${ }^{4}$ Coma has also been described after therapeutic doses of cimetidine ${ }^{5}$ but not after overdose. In animal studies extremely high doses of cimetidine caused tachycardia, convulsions, and respiratory depression, and the oral $\mathrm{LD}_{50}$ in dogs was about $2600 \mathrm{mg} / \mathrm{kg}$ (Amos, personal communication). Many drugs cause serious toxic effects in overdose, but from experience gained so far self-poisoning with cimetidine does not seem to be dangerous.

We thank Drs A T Proudfoot, L F Prescott, and M J Stewart for advice, and Mr J C Amos (Smith Kline and French Laboratories) for information about cimetidine. 2 Gill, G V, Lancet, 1978, 1, 99.

${ }^{3}$ Curtes, J P, and Develay, P, Bulletin de Médicine Légale, Urgence Médicale,

${ }^{4}$ Jefferys, D B, and Vale, J A, Lancet, 1978, 1, 828.

5 McMillen, M A, Ambis, D, and Siegel, J H, New England fournal of Medicine, 1978, 298, 284.

(Accepted 14 December 1978)

Regional Poisoning Treatment Centre and Department of Clinical Chemistry, Royal Infirmary, Edinburgh EH3 9YW

R N ILLINGWORTH, BM, MRCP, medical registrar

D R JARVIE, BSC, PHD, senior biochemist
${ }^{1}$ Randolph, W C, et al, fournal of Pharmaceutical Sciences, 1977, 66, 1148. Centre Anti-Poisons, 1977, 20, 137.

good and interpretation was not affected. Ther was no evidence of the equivalent of a "jelly short" occurring with water. There was no significant difference in the quantity of discarded paper between the two methods.

\section{Comment}

With the early string galvinometer machines there was a low input impedence, and electrolyte pastes and jellies were necessary to overcome skin resistance. With the high input impedence of modern instruments, however, any liquid that moistens the skin will give a satisfactory recording-water, toothpaste, french mustard, and even marrons glacés have all been shown to be as effective as jelly. ${ }^{1}$

The main advantage in using tap water rather than jelly is economy. The cost of jelly is about $£ 2$ per 100 ECGs. Swabs used to apply and remove the jelly at a rate of at least two per ECG cost some 42 p per 100 ECGs, whereas with water (which does not have to be dried) 20 swabs will suffice for at least 100 ECGs, or a damp sponge or towel may be used repeatedly, thus removing this expense entirely. By using the tap water there is, therefore, a saving of about $£ 3.50$ per 100 ECGs, which in a 300 -bedded general hospital would amount to about $£ 100$ annually. The technician's time is also spared: it is easier and quicker to dampen a swab than to squeeze jelly from a tube (which may not be available in an emergency), and there is no need to clean the skin after recording. Furthermore, straps and electrodes do not need cleansing, and the electrodes do not erode with water.

Because of these advantages, we recommend that electrode jelly be replaced by tap water in the routine recording of ECGs.

We are grateful to Dr J Fielding who kindly helped to analyse the ECGs.

${ }^{1}$ Lewes, D, British Heart fournal, 1965, 27, 105.

2 Lancet, 1965, 1, 975.

${ }^{3}$ Maxwell, J, British Medical fournal, 1957, 2, 942.

(Accepted 19 December 1978)

The Charitable Infirmary, Jervis Street, Dublin

ANN MARTIN, LRCPSI, senior house officer

RITA TIERNAN, MSCT, technician

MARY D'ARCY, LRCPSI, senior house officer

EOIN O'BRIEN, FRCPI, MRCP, physician (cardiology)

\section{Tap water instead of electrode jelly for electrocardiographic recording}

Pleas for replacing expensive and messy electrode jelly with simple lubricants ${ }^{2}$ or even water $^{2}$ have largely been ignored, and it is common practice to use one of the commercial electrode jellies for hospital and domiciliary electrocardiographic (ECG) recording. The purpose of this paper is to show that using water instead of jelly does not detract from the quality of the ECG.

\section{Patients, methods, and results}

One hundred patients referred to the ECG department were randomly selected for study; the criterion for selection was the time available to the technician for recording and mounting the extra tracings. We have used water rather than jelly for some time, so the first or service ECG was recorded using water without any other skin preparation, and the second tracing was then taken using one of the commercial electrode jellies. Both traces were mounted separately and when the study was completed two physicians each examined 100 mixed tracings which did not indicate whether water or jelly had been used. These traces were carefully examined for quality and were assessed for alternating current interference (50 cycles per second), wandering baseline $(+$ or $-5 \mathrm{~mm})$, and other artefacts. One technician recorded all ECGs with a Siemens Cardiostat $3 T$ (input resistance, standard leads: $2 \times 5$ MOhm (between R-L, L-F, F-R with aV and V leads: 600 KOhms); frequency response: $0-100 \mathrm{~Hz}, 5 \mathrm{~dB} ; 50-\mathrm{Hz}$ filter on mains only; battery power used for traces in this study) or Cambridge VS4 (input impedence: $>500 \mathrm{kOhms}$ between any patient lead and ground under any conditions; frequency response: 0.08 to $40 \mathrm{~Hz}+0.5 \mathrm{~dB},-3: \mathrm{dB}$; this machine did not have a Hertz notch filter). Electrode size was $3.8 \times 5 \mathrm{~cm}$ for the Siemens machine, and $3.8 \times 6.2 \mathrm{~cm}$ for the Cambridge. Tracings were taken in the ECG department, which is not specially shielded against AC interference.

All tracings-that is, 100 with jelly and 100 with water-were regarded as satisfactory for routine interpretation. The amplitude of the QRS complexes was not changed by using water, nor were there any significant differences in the $S-T / T$ segments between the two techniques. Two tracings (one water, one jelly) were deemed "satisfactory but not a good tracing" due to the presence of alternating current interference. Slight alternating current interference was present in a further 10 ECGs (4 jelly, 6 water) but did not affect the overall quality of the tracing. A wandering baseline was present in one lead of six tracings ( 3 water, 3 jelly), but again the overall quality was

\section{Movelat in the prophylaxis of infusion thrombophlebitis}

The incidence of infusion thrombophlebitis is reduced when very small doses of heparin and hydrocortisone are added to the bottles of infusion fluid. ${ }^{1}$ It was therefore decided to test the prophylactic effect of these drugs as a skin cream.

\section{Patients, methods, and results}

One hundred identical tubes were prepared and numbered consecutively. Half contained active cream and half an inert placebo cream, allocated randomly according to a code held by the statistician. The active cream, Movelat, contained $1 \%$ adrenocortical extract (equivalent to $20 \mathrm{mg}$ of corticosteroid), $0.2 \%$ organoheparinoid, and $2 \%$ salicylic acid. Patients were asked to join the trial if they needed an intravenous infusion that was likely to last for $\mathbf{4 8}$ hours or more. Those receiving intravenous feeding or whose drips were used to administer uncommon drugs were excluded. A Medicut cannula and Baxter giving-set were used for every patient. Each patient entering the trial was alloted the next numbered tube of cream and when the infusion was completed that tube was discarded. The cream was applied three times daily to the skin over the drip vein from the puncture site proximally for about $20 \mathrm{~cm}$. The skin was examined daily for signs of thrombophlebitis; only when there was thrombosis of at least $25 \mathrm{~mm}$ was this considered a positive finding. The drip was discontinued when clinically indicated or when thrombophlebitis supervened. When 100 patients had entered the trial the code was broken and the results analysed.

Three patients were eliminated, two because the conditions of the protocol were not fulfilled and one because he died before the infusion was completed. Ninety-seven results were analysed. Forty-eight patients were found to be in the treatment group and 49 in the control group; the distribution of patients by sex, age, and diagnosis between the two groups was closely similar. 